Charles Bazerman

\title{
3 Scientific Knowledge, Public Knowledge, and Public Policy: How Genres Form and Disrupt Knowledge for Acting about Anthropogenic Climate Change
}

\begin{abstract}
Knowledge about anthropogenic climate change is produced, stored, and accessed in specific genres associated with different activity systems. Alignment of knowledge across spheres facilitates coordinated action among diverse groups. Our knowledge of the environment has been created in recent history by the interaction of discourses in military, scientific, public, political, corporate and governmental spheres. These spheres do not always work in concert, with significant obstacles and even resistances to communication of knowledge across boundaries. Citizen concerns, expressed in public genres, have been crucial over the last sixty years in creating environmental knowledge, in contrast to governmental or corporate interests, even though government has since taken on major responsibilities for the production, dissemination, and authentication of environmental information. Those with a desire to disrupt remedial action on the environment and more particularly anthropogenic climate change have found disrupting the certainty of knowledge within governmental genres an important tool. ${ }^{1}$
\end{abstract}

\subsection{Introduction}

Cooperation on action to mitigate anthropogenic climate change requires the committed engagement of people of many countries with many different interests. Concerted and effective action mitigating climate change requires that these many groups recognize that an urgent problem exists, that the problem has particular characteristics, and that certain actions will likely be effective. Further they must agree that the situation is so dire and of such great priority that they will be willing to sacrifice other valued goods and to make adjustments to well-established ways of life and business.

This alignment over the existence, urgency, and solutions to anthropogenic climate change requires that each of these groups understand, trust, and accept the importance of a series of scientific findings, theories, and projections. To understand, trust, and accept this scientific work requires that they learn to engage with and make sense of the many kinds of professional knowledge that have transformed

1 An earlier version of this chapter appeared in Linguagem em (Dis)curso, (2010, 445-463).

(c))BY-NC-ND (C) 2020 Sune Auken and Christel Sunesen

This work is licensed under the Creative Commons Attribution-NonCommercial-NoDerivs 4.0 License. 
our view of the climate. Climate knowledge is grounded within, and gets evidentiary warrant from certain citizen-oriented scientific genres. This knowledge is then taken up (Freadman, 1994, 2002) and operationalized into public, government, and corporate action through other genres. The problems and solutions are only identifiable and persuasive through the forms of evidence, calculation, and reasoning existing in these genres. Insofar as people are not skilled in engaging with these genres they are not able to build trust and engagement with the solutions, even if they accept the authority of the texts and their authors. It is only through these genres that we know, and it is only when we know that we can act with energy and conviction (for the demotivating effects of uncertainty of climate change knowledge see Cook, Lewandosky, \& Ecker, 2017; Lorenzoni, Nicholson-Cole, \& Whitmarsh, 2007.)

The case of anthropogenic climate change shows how knowledge is produced, stored, accessed, and deliberated upon in specific genres within specific activity-oriented social formations, and then how that knowledge may or may not be transmitted into other activity systems. What is known in one activity system is not immediately and automatically known in another. Genres must exist that allow for the transmission following specific procedures and criteria; further, writers must carry out that work of translation in these intermediary genres (Tachino, 2012). Individuals or groups with stakes in the deliberations of the receiving activity system may then seek to control which knowledge enters into the new system and how it may influence decisions to be made upon that knowledge by contesting the legitimacy of the transmission (Bazerman, 2009, 2013).

The phenomenon of anthropogenic climate change itself cannot be directly and reliably experienced by any individual, nor is it even directly visible from the inspection of typical local weather records (Moser, 2010). Seeing anthropogenic climate change as a phenomenon, let alone recognizing that it poses a problem, requires a kind of professional vision (Goodwin, 1994), seen through the lenses of scientific theories and literature, aggregated planetary data, and computer models. Awareness of our problem depends on projection of future conditions by those computer models, as is identification of potential remedial actions. Without trust in those aggregated data, models, and projections, climate change is hard to recognize. The problem anthropogenic climate change poses has gained widespread attention of the scientific public only in the last four decades and of citizens and governments only in the last two. While there is high agreement in the scientific community and strong consensus that action is needed (see, for example, Cook et al. (2016) and the introduction to this volume), agreement and action consensus among citizens is uneven although increasing as a result of extreme weather events now commonly attributed to climate change (Moser, 2016). Further, cooperation among governments is only recent, and corporate engagement is only sporadic and subordinate to perceived interests. Our future hangs on gaining more consistent engagement with scientifically based knowledge and its policy imperatives. 
This essay examines that process of social learning and alignment to relevant scientific knowledge, from a genre and activity theory perspective. In this essay I will be bringing together the work of a number of my prior studies where more detailed evidence and analysis are available (Bazerman, 2001; Bazerman, Little, \& Chavkin, 2003; Bazerman \& de los Santos, 2005). These studies are based predominantly on events and evidence from the United States, but given the US role in science and in the international economy along with the recurring episodes of US governmental and corporate recalcitrance, the harnessing of US political will is an important element in global negotiations on addressing climate change. Thus, this story is of more than local interest. In addition, because cooperation of people and organizations in every nation is essential for effective global climate cooperation we need similar understandings of the formation of politics and policy in each nation and region.

\subsection{Knowledge Resides within Genres}

Theoretically, the studies in the present volume are grounded in the idea that knowledge is inscribed, reasoned about, stored, and accessed in specific genres. Bakhtin noted that each genre is associated with a specific time and space, or chronotope, populated by expected types of characters, objects, scenery and other elements, which then are part of an expected set of unfolding of events (Bakhtin, 1981). Some genres in fact exist with the specific aim of producing, warranting, evaluating, or distributing specific forms of knowledge (Bazerman, 1999). Engaged and knowledgeable participants in activity systems know where relevant knowledge is to be found. This is an extension of the observation that most of what we consider knowledge is embodied in linguistically produced artifacts, typically in a written, rather than purely spoken form. Different kinds of knowledge are produced, warranted, and used by particular groupings of people who are bound together by series of publications and related communicative forums in which the typical genres of the groups are produced, rehearsed, and discussed (Bazerman \& Rogers, 2008). Further productions are intertextually linked to prior texts and the knowledge produced therein. Evidence, including empirical evidence gathered from outside the textual world, must be gathered and inscribed by methods and forms that are accepted within the knowledgeproducing social group. Only then is the evidence available for evaluation and as warrant for further knowledge claims. This production, collection, and mutual articulation of knowledge and evidence within disciplinary or professional forms create the basis of coordinated future action.

When actions require cooperation across many groups of people, it is important that knowledge is taken up from one sphere of coordinated knowledge to another. This is a consequence of the fact that different communicative spaces - particular genres within particular activity systems - gain the attention and belief of different groups of people, and knowledge does not readily flow from one to another. For example, 
the rules and purposes of evidence within the law are very different than those of science. If scientific knowledge bears on a court case, elaborate procedures for carrying information across the boundaries transform the nature and particulars of the knowledge as well as their operational effect, often leaving scientists unhappy with what knowledge gets to the courts (see Bazerman, 2009). Thus, large group actions involving many people in many different roles and configurations must somehow coordinate their different kinds of knowledge to share recognition of a problem to be addressed; otherwise, the groups will not be able to act with mutual clarity, conviction, and commitment.

\subsection{Knowing the Environment}

So how do we know the environment? While we may walk through forests and enjoy the sounds of birds and refreshing breezes, when we talk of the environment we are more likely to have in mind things we have read - in public media drawing on specific scientific literature. Indeed, until recent decades we would not even be likely to refer to ambient nature as an environment, let alone as an interdependent system. Even among scientists the concept of environment was an invention of the mid-nineteenth century (Jessop, 2012) and ecosystem of the 1930's (Willis, 1997). Both remained of limited attention and interest until the latter half of the twentieth, circulating only in a limited set of genres within some biological specializations. Few scientists, let alone policy makers or citizens, had reason to turn to the pages of journals where the concepts resided.

Within the US public sphere, Rachel Carson's drawing together of the work of researchers whose work had not formed a coherent body of knowledge marked the introduction of the idea of environmental threat as she publicized the problems created by DDT and other pesticides. Earlier concerns about pollution, such as air pollution from industrial and vehicle emissions were seen more as problems of direct contamination rather than systemic degradation. Carson herself was a government naturalist, who had written a number of popular books of nature appreciation. In writing Silent Spring (1962, 1995), she created a compelling public account that changed the public's ways of viewing their actions as potentially having long-term systemic consequences on the conditions of our life as ramified through complex interdependent processes (see Waddell, 2000 for useful contexts and analyses of Carson's book). The wide circulation of Silent Spring created political and policy discussions leading to government regulation of pesticides. This pesticide legislation differed from earlier food and drug regulation by controlling small amounts of chemicals that, though not immediately destructive, would have long range aggregate consequences. This kind of reasoning and the need to have associated regulation gave rise to new scientific specialties such as ecotoxicology that statistically calculated long term results under field conditions in contrast to the controlled laboratory experiments of traditional 
toxicology (see Bazerman \& de los Santos, 2005 for a study of the divisions and reconciliations that impeded and eventually allowed evidence to travel between genres of these specialties). We can also see the continuing effect of the communicative model Carson created in the introductory comments of Al Gore to the 1995 reissue of Silent Spring, indicating the direct genre genealogy of Earth in the Balance (Gore, 1992).

For me personally, Silent Spring had a profound impact. It was one of the books we read at home at my mother's insistence and then discussed around the dinner table. My sister and I didn't like every book that made it to that table, but our conversations about Silent Spring are a happy and vivid memory. Indeed, Rachel Carson was one of the reasons I became so conscious of the environment and so involved with environmental issues. Her example inspired me to write Earth in the Balance, which, not coincidentally, was published by Houghton Mifflin, the company that stood by Carson through all the controversy and that has since earned a reputation for publishing many fine books about the environmental dangers facing our world. (Gore introduction to Carson, 1995)

Concurrently, another set of events was creating a related set of genres at the intersection of science, public issues, and government policy (Bazerman, 2001). We can pick up this story with the Manhattan Project, which developed the atom bomb under conditions of the highest secrecy. Under the exigencies of WWII, academic science, which had been used to the free flow of information, acquiesced to the military discipline of a restricted flow of knowledge. After the Hiroshima and Nagasaki atomic detonations and the end of the war, scientists exerted pressure to allow open access to the scientific findings (Smith, 1965). Advocates of civilian monitoring and democratic decision making also wanted the science to be publicly available. The rapid emergence of the Cold War created new pressures for secrecy, so that major restrictions remained (monitored by the newly-formed Atomic Energy Commission) keeping much of the knowledge about nuclear weaponry and its effects within classified military documents. However less than a decade later, after atmospheric testing of hydrogen weapons produced radiation fallout, public pressure increased for more detailed information about the effects of fallout, particularly strontium 90 (Wittner, 1997). Strontium 90 was chemically similar to calcium, thus fallout onto grasslands was ingested by cows and concentrated in milk. Children drinking milk from contaminated cows would then further concentrate the strontium 90 in their bones and teeth.

After government and military sources remained vague on details about fallout and its effects despite public pressure, an alliance between academic scientists and citizen groups formed in St. Louis to make knowledge available and pressure for limiting testing and the associated nuclear fallout (Sullivan, 1982). The St. Louis Citizens' Committee for Nuclear Information began producing newsletters called Information, then Nuclear Information. Those newsletters provided scientific knowledge from the perspective of public problems, though presenting the political message only by implication. The selection and organization of the texts, nonetheless, clearly made evident governmental actions were putting citizens at threat by disrupting the safe environ- 
ment for human life. The organizers of this movement were self-conscious about advancing citizen science in the public interest, and were gathered by scientists who considered themselves as citizens, rather than being in the employ of government, military or industry. Such scientists would develop their research questions from public need rather than the internal dynamics of science. The direct linkage between this movement and the environmental movement is indicated by the name changes of the newsletter as it transformed into a journal. Nuclear Information became retitled Scientist and Citizen and then Environment. Even as the articles became more technical they kept the focus on public problems (Bazerman, 2001).

The increasing public concern for the environment became a major political issue to which Congress responded with the National Environmental Policy Act of 1970. The perceived lack of information available on which to base policy led to the requirement that an Environmental Impact Statement be produced for any government action that might affect the environment. The adequacy of this new genre created by fiat has been a matter of debate; nonetheless, the genre both monitored actions from the citizen's perspective and expanded the market for the production of such information. Further, it identified governmental agencies as responsible parties for the collection of such information, taking some of the impetus away from grassroots citizen groups (Bazerman et al., 2003).

So in less than twenty-years we had new communication channels that fostered public attention and access to certain kinds of scientific information viewed as relevant for public well-being, particularly because the normal conditions of life were under threat by human actions. These new communicative channels created a market for scientists who would adopt a public interest perspective. These channels in turn fostered new developments within more purely scientific and political communities.

\subsection{Knowing about Global Warming}

Among the issues taken up in these new communicative spaces was global warming, as it was then called. Awareness of global warming also had begun in military sponsored science. While the concept of greenhouse warming of the atmosphere was first proposed by Fourier in the 1820's and revived by the engineer Callendar in 1850, it initially gathered little attention, and little evidence suggested its reality. Military interests in the Cold War period, however, led to monitoring of the oceans and atmosphere as potential sites of military engagement. Working for the Office of Naval Research, Roger Revelle in 1957 noted that recorded ocean uptake of excess CO2 was less than anticipated, which meant that atmospheric $\mathrm{CO} 2$ produced by hydrocarbon combustion would be increasing (Weart 2003, 2008). To track this and similar data the National Center for Atmospheric Research was founded in 1960. In 1970 this agency was reorganized under a new National Oceanic \& Atmospheric Administration (NOAA) in the Department of Commerce. Most of the foundational research on 
global warming at that time and since has been done by governmental agencies or under related government funding, often tied to national security concerns, though increasingly with attention to the potential disruption of everyday life of citizens in the US and elsewhere. James Hansen, perhaps the leading figure in global warming science, was employed at the NASA Goddard Institute for Space Studies in New York City from 1972 to 2013 and was its director from 1981 until he left the Institute. NASA, although an independent government agency, has been from its founding deeply intertwined with military interests; nonetheless, it has increasingly addressed more general citizen concerns.

Much of global warming research has been based on computer models of global and regional climates, with historic data and projections forward, looking to climate impacts and turbulence, as well as impacts on sea level, agriculture, and other climate sensitive phenomena. Recognition of this broader view of the complex impacts of increasing greenhouse gases has led to the current preference for the term climate change, with the even more recent preference for the term anthropogenic climate change, recognizing the role of humans in producing greenhouse gases. Even today, nonetheless, all three terms are in use by different participants, and in the following historical account I will follow the usage of each participant I am discussing.

Climate models always have a degree of speculation, extrapolation, and simplification so authoritativeness and certainty was an issue from the beginning, with many competing models and projections, using both different data collections and different algorithms. Nonetheless, by the mid 1980's, an increasing numbers of reports raised alarms about potential harm (see http://www.globalwarmingarchive.com/Timeline. aspx). In particular governmental reports from the Environmental Protection Agency in 1983 made public concerns that climate change would begin to be evident in the 1990's with serious consequences for food production and sea levels. The New York Times article describing this report had to provide not only an introduction to the scientific principles of greenhouse warming, and a survey of the evidence, but also a discussion of the nature of the computational models with their uncertainties (Shabecoff, 1983). The public needed to be educated into the scientific issues and given a primer on atmospheric science in order to understand the issue, evidence, and specialized form of argument.

The EPA report indicated that by 1983 strong scientific consensus had already emerged that serious climate change would be occurring because of human produced carbon dioxide, though there were some differences on timing and severity. A series of UN sponsored scientific panels also tracked the solidifying scientific consensus. In 1988 the World Meteorological Organization and UN Environment Programme formed the Intergovernmental Panel on Climate Change (IPCC) (http://www.ipcc.ch/). The first assessment report of the IPCC in 1990 expressed some differences and uncertainties about the specific scenarios that might unfold, but confirmed the importance of the issue and established a framework for addressing the climate change issue and gathering data for future reports. The second assessment report in 1995 confirmed 
with confidence the existence and magnitude of global warming and offered specific projections. This report formed the framework for deliberations of the Kyoto Protocol in 1997. The third assessment in 2001 presented strong evidence that change had already occurred, examined the mechanisms of the change, and offered options for intervention. The fourth assessment in 2007 noted substantial effects that had already occurred and will be continuing, and offered scenarios that might mitigate the consequences. The fifth assessment in 2014 reported that human activity had raised emissions of greenhouse gases to the highest in history, already impacting human and natural systems, with greater impacts and risks to come, even if emissions were to be stopped immediately. The assessment identified some pathways for mitigation and adaptation to reduce the worst risks, and became a central background document to the Paris Agreement of 2015. The sixth assessment is scheduled to be completed in 2022.

\subsection{Knowledge for Policy Action}

It is quite unusual for adjudication panels to be formed in science, as codification of knowledge is usually left to implicit processes of review, citation, and incorporation into future work, reviews, and textbooks (Bazerman, 1991). The EPA and IPCC reports, based on panel judgments and circulation among wide numbers of scientists for their approval, indicate firstly the intersection with policy and public concerns and secondly that governmental action and intergovernmental cooperation require a high degree of sharing of knowledge considered authoritative and trustworthy. A citation count or review of the literature is not an adequate sign of scientific agreement for governmental policy action. Rather a governmentally or intergovernmentally authorized body must authenticate findings with the explicit comment of a wide sample of the authoritative scientists in the area.

But scientific consensus, even government-authorized adjudication of consensus, is not enough for concerted action. The knowledge needs to gain the belief and commitment of segments of the population and institutional groups who will have to cooperate with the action. Earlier citizen engagement with environmental knowledge had already spread through journalism, specialized reports, and non-fiction public problem policy books by the 1990's laying the grounds for public knowledge and substantial public consensus that climate change was occurring. By 1992, 68\% of the US public believed that global warming was real as a phenomenon - a number, that despite a dip in 1994 - has since only increased to around 75\% with under $20 \%$ skeptical. Recent polls indicate that concern about global warming continues to increase along with belief that effects are already being seen (Saad, 2017). Curiously, however beliefs about scientific certainty lagged behind with $28 \%$ of the sampled public believing that there was scientific certainty in 1994, $46 \%$ percent in 1997, $61 \%$ in 2001 and $65 \%$ in 2006 . The bulk of the other responders, however, rather than exhibiting 
belief that scientists were not convinced rather stated they were unsure (58\% in 1994 , $37 \%$ in $1997,30 \%$ in 1991 , and $29 \%$ in 2006). This indicates that the overwhelming certainty among scientists, expressed in the 1983 EPA and 1995 IPCC reports was not being communicated clearly to segments of the public, even though awareness of the phenomenon had. In 1994 there was a 29\% disparity between citizens' own certainty and their estimate of scientific certainty, $21 \%$ in 1997, 16\% in 2001 (Nisbet \& Myers, 2007). More recent polling, however, indicates greater public awareness of scientific consensus (Saad, 2017).

Government under the Clinton administration also expressed strong alignment with knowledge about global warming, evident in reports, websites and other documents, as did the Congressional Office of Technology Assessment reports in the early 1990's (though Congress eliminated the agency in 1995). The Clinton Administration was also active in negotiating and supporting the Kyoto protocols in 1997. Vice President $\mathrm{Al}$ Gore in particular advanced many environmental initiatives and advocated for the Kyoto Protocol.

\subsection{Interfering with what Publics and Governments Know}

Republican control of Congress in 1994 and the Bush presidency in 2001 changed the stance of branches of government and their role in the knowledge process, following the interests of the corporate sector. The corporate sector generally resisted the emerging consensus about global warming and did its best to disrupt communication and alignment of knowledge within the public and government. This is the story behind the Republican Congressional opposition in the 1990s, the Bush positions, and the curious anomalies in the public perception of science.

But before we go into the specifics of the activities of the corporate sector, particularly the energy sector, we need to look at the underlying causes of the stance they take toward the environment from a genre and knowledge perspective. Businesses typically have a short to middle range time horizon on making financial decisions to enhance profitability and growth in the foreseeable future, usually from one to eight years (Das, 1987; Naylor \& Schauland, 1976). The uncertainty of long range, or even middle range, economic forecasting also mitigates against longer planning. What planning does occur has to rely on historic conditions and trends. Thus, the genres that collect knowledge for decision-making and then attempt to extrapolate forward consider the future much like the past. Projections beyond the immediate upcoming quarters and years fade from view, particularly futures that might incorporate radical changes in conditions. In publicly held companies, further, maintaining or increasing stock prices through growth of quarter-to-quarter profits keeps calculations even more in the near term. This short time frame has been further tightened by the tying of executive compensation to stock prices through options and bonuses. In this short to middle time frame, climate change does not turn up substantially in past or projected 
balance sheets and thus does not seriously enter into calculations. Losses through extreme weather and other natural disasters are covered by insurance. At worst, increased risk of climate induced disasters turns up as increased casualty insurance premiums - in most industries not a significant cost. It is only when predictable changes in sales might occur as a result of changing consumer needs and desires (such as a cultural preference for green products) or changes in production costs (such as caused by climate-related agricultural shortages) would the climate really be worth taking into account. Government regulation and other mandated adjustments might put greater pressure on the business model, and thus concerted government action on climate change would be more of a threat to projected profitability (the core goal in corporate economic planning) than direct loss from global warming.

The insurance industry, however, has for centuries had a longer time frame for data gathering and planning. Since its business is built on balancing current income against rarely occurring events, the insurance industry since the seventeenth century has developed actuarial tools of determining long-term costs and risks and matching that to current income and profitability. Accordingly, the insurance industry has developed genres for displaying the long-time frame and calculating profit within it. Even more directly, climate-induced disasters incur direct business expenses and cannot be laid off to anyone else, except maybe the large reinsurers. Therefore, it is quite understandable that insurance, with the reinsurers leading the way, was the first industry to recommend action on global warming. By early 1990s some European insurers became concerned with global warming's impact on their industry (Mollin, 1993). Large reinsurers such as Munich Reinsurance Company hired their own meteorologists and climatologists to prepare internal reports (Mills, 1998). Indeed, the industry began encouraging eco-friendly behavior and basing investments on environmental and sustainability audits (Hoeppe \& Berz, 2005).

But for most industries, action to mitigate climate change was calculated to be more costly than the effects of the change itself. Climate change action might even require a fundamental restructuring of industry and restriction on business. The oil, coal, and electrical power industries, in particular, began to pay worried attention to predictions about global warming as early as the late 1970s before any substantial public, political, or public policy awareness had emerged. But as scientific knowledge gained activist, political and even government attention, suppressing information about global warming became less possible. Instead, the energy sector adopted a strategy to disrupt the confidence and direction of the emerging public discussion of what, if anything, needed to be done. This tactic, called agnotology (Proctor \& Schiebinger, 2008, see also Michaels, 2008) - the active production of uncertainty was first developed by the tobacco lobby to maintain the appearance of "controversy" which undermined certainty of knowledge with its imperative for action. The strategy was carried out by producing the appearance of scientific disagreement through magnification of minor differences and the sponsored production of legitimate seeming but questionable research that appeared to contradict more independent and solid 
work. Then, on the basis of this manufactured appearance of uncertainty, lobbies could argue for more research, delays in action, or simply avoiding action that might appear as an expensive and unnecessary gamble.

One of the key organizations for this production of disruptive knowledge about global warming became the George C. Marshall Institute, which had previously been engaged in arguing for Reagan's Strategic Defense Initiative, known as Star Wars. Interestingly, two of the key players in this organization as it turned its attention to energy had long experience with the production of quasi science for the tobacco lobby. S. Frederick Seitz, chair of the Marshall Institute, was a consultant to tobacco company RJ Reynolds until 1989. S. Fred Singer, who authored 35 Institute-sponsored articles and books questioning global warming, had also learned this strategy through tobacco research (Oreskes \& Conway, 2010). As part of the same strategy, ExxonMobil beginning in 1987 sponsored a series of misleading public statements questioning climate change (Supran \& Oreskes, 2017), and after the negotiation of the Kyoto accord funded the "Cooler Heads Coalition" to argue against US ratification.

The energy lobby found its allies in the political sphere where they brought the knowledge disruption tactics first to Congress and then to the Bush administration, so government deliberations also could not be carried out in an atmosphere of scientific certainty. Frank Luntz, a chief Republican political strategist, in a 2002 memo urged the Republicans to "make the lack of scientific certainty a primary issue" (Burkeman, 2003). Republican Senator James Inhofe, who since his election to the Senate in 1994 had called global warming a fraud, in 2003 became chair of the Senate Committee on Environment and Public Works and organized hearings to make that case. When George W. Bush became president, his administration almost immediately announced it would not implement the Kyoto Protocol. Further, the White House then began to participate in the disruption of public certainty about scientific knowledge. Previous reports were expunged from the EPA website, and new scientific reports were edited by a lawyer Philip Cooney who had previously been a lobbyist for the American Petroleum Institute. His handiwork typically involved adding words such as perhaps, maybe, or uncertainty at key locations in scientific reports that had originally been drafted with full certainty (Revkin, 2005). The US National Assessment on Climate Change, mandated by the UN, was near silent on global warming. The 600-page draft of the 2003 report had only six paragraphs on climate change; the White House then deleted five and added a reference to an ExxonMobil-funded study disputing the global warming hypothesis (Revkin, 2003). So as to further disrupt the flow of substantial scientific information, James Hansen, still head of the Goddard Institute, was ordered not to speak publicly on global warming issues. Only under court order, in its closing days, after a four-year delay and too late to influence any policies, did the Bush administration release a legislatively mandated report of the impact of global warming (Revkin, 2008).

The new Obama administration in 2009 realigned with scientific knowledge, with new government reports, websites, and proposals acting in consonance with science. 
Extensive scientific data was made publicly available through the websites. The administration supported legislation to decrease carbon dioxide through cap-and trade - which creates economic incentives by setting emissions allowances which can then be traded on a market. Gaining congressional approval, however, presented a challenge and no law emerged, as will be examined in the next chapter in this volume. Nonetheless, the Obama administration engaged in international negotiation in Copenhagen in 2009 and Paris in 2015, resulting in the Paris Agreement, to which the US committed by executive action, avoiding Congressional deliberation. Despite congressional resistance to the accord, the Obama administration began implementing the commitments through his previously initiated Presidential Climate Action Plan and Clean Power Plan.

The election in 2016 of Donald Trump, however, again reversed direction. While Trump earlier in his career had, prior to the Copenhagen climate conference, co-signed a paid advertisement in The New York Times on December 6, 2009 calling for action on climate change (Adler \& Leber, 2016; Davenport \& Lipton, 2017), as a candidate he repeatedly claimed climate change was a hoax for the benefit of the Chinese, scientists, and other interests. Immediately upon his inauguration, the EPA and other governmental sites began to remove climate change data or make it less accessible (Davenport, 2017; Mooney \& Eilperin, 2017). In anticipation of the Trump's administration's attempt to change the public record on climate change, scientists began to preserve on independent servers the data from US government websites (Dennis, 2016; Holthaus 2016). Trump also withdrew Obama's Presidential Climate Action Plan and Clean Power Plan (Davenport \& Rubin, 2017) and announced his intention to withdraw the U.S from the Paris Agreement. While the Trump administration has obscured where it stands on climate change and climate change denial has regained force with the political right (Davenport \& Lipton, 2017), local jurisdictions such as states (Bromwich, 2017), cities, universities, and corporations have aggressively regulated greenhouse gases and invested in green energy and other technologies. Consortia of these local jurisdictions are forming to coordinate their efforts (Tabuchi \& Fountain, 2017) and have the potential of entering into international efforts in lieu of national US withdrawal (Hernández \& Nagourney, 2017).

So, we are now in a position in the US where different groupings of people know different things, with different collections of knowledge visible within their systems of reasoning, justification, and calculation. This is despite almost all other countries now being in agreement as signatories of the Paris Agreement and implementing related domestic policies, including China, India, and the EU. In the US however, the efforts of different groups pull in different directions and remain uncoordinated, lacking a common understanding of the problems facing society as a whole, let alone how they can pursue their separate interests and concerns within a shared set of facts. The state of knowledge within each of these systems is the product of ongoing epistemic work of creating effective speech acts or contesting the speech acts of others, to 
leave sets of facts standing, obliterate others, or create uncertainty to weaken the will and focus of action.

Within the uncertainties that face us as the material, political, and economic situations unfold on the global stage, one thing seems certain: what people do depends on what the social and institutional groups that they participate in know, and that what these groups know is the result of active rhetorical work to represent and justify the knowledge which is the basis of problem definition and action. That struggle for which knowledge gets represented with the certainty that demands action will not end until the problem is considered resolved or moot for all interested parties. For example, at one time the genealogy of various European royal families was a major concern to establish legitimacy of regimes, but now it is mostly moot as political changes have made claims of royal lineage matters mainly for the social register. Similarly, complex identification and parsing of various sins and their place in various circles of hell are no longer much of a theological concern. But the facts of climate change are currently very much of a concern, with impacts for all and needed engagement of all in solutions.

\subsection{Final Comments}

This chapter highlights how certainty of knowledge comes about through coordinated information within key knowledge genres in each sphere, how certainty expressed in the genres of one sphere does not necessarily translate into certainty of knowledge in others, how alignment of knowledge across the genres of different spheres is necessary for coordinated action on complex matters, and how disruption of knowledge translation can be disruptive of action. With respect to the environment the case of anthropogenic climate change has highlighted the centrality of science as a producer of authoritative knowledge; the necessity and difficulty of getting other spheres to attend to and understand the scientific consensus in order to incorporate the findings into their reasoning; and the power of disrupting that process of shared knowledge construction and deliberation. Further, this case has highlighted the role of the federal government within the US system has taken as a central gatherer, authorizer, disseminator, and site of action calculation - and how disrupting government processes of knowledge can disrupt action initiatives, even when science and the public remain convinced of anthropogenic climate change, and the disruptive insertion of distracting claims and inappropriate doubts is transparently obvious to all players. Not only does disruption of government knowledge stall the internal deliberations and actions of the US government, but also places major obstacles within international climate negotiations.

Finally, while national governments play such a central role in the production, sponsorship, authentication, and dissemination of knowledge as well as its direct use for deliberation on action, we should remember that all governments are beholden to 
many forces and pressures. While the US government took on some responsibility for the citizens' need for knowledge and action, citizens as citizens are not its only client. Actions in the name of citizens can often be betrayed or hijacked by other interests, so that citizens must maintain citizen genres of knowledge production and evaluation of knowledge from other spheres. They must then monitor government knowledge and actions within certain genres of inspection and evaluation, and must mount political pressure through various communicative genres to hold the government to its responsibility for maintaining and acting on solid science in the public interest. However, when government defaults or draws back, disrupting what is known from scientists, other actors, such as industry, activists, individuals, and other political jurisdictions can attempt to step in. These in turn may become political forces that will impact the government, as political knowledge is the specialty of governments, and it cannot deny the facts of political forces as long as a semblance of democratic procedures remain. Vote counting, fundraising, actions of other government bodies in a distributed federal system with separation of powers among branches - these form facts that are noted and calculated within democratic governments whether climate knowledge is viewed to be firm or uncertain.

\subsection{Postscript}

At this time of final editing in the midst of the Covid-19 pandemic, the implications of this study for government and citizen action or inaction are even more immediately salient.

\section{References}

Adler, B. \& Leber, R. (2016, 8 June). Donald Trump once backed urgent climate action. Wait, what?. Grist. Retrieved from http://grist.org/politics/donald-trump-climate-action-new-york-times/

Bakhtin, M.M. (1981). The dialogic imagination. Austin, TX: University of Texas Press.

Bazerman, C. (1991). How natural philosophers can cooperate: The rhetorical technology of coordinated research in Joseph Priestley's History and present state of electricity. In C. Bazerman \& P. Paradis (Eds.), Textual dynamics of the professions (13-44). Madison: University of Wisconsin Press.

Bazerman, C. (1999). Singular utterances: Realizing local activities through typified forms in typified circumstances. In A. Trosberg (Ed.), Analysing the discourses of professional genres (25-40). Amsterdam: Benjamins.

Bazerman, C. (2001). Nuclear information: One rhetorical moment in the construction of the information age. Written Communication, 18(3), 259-295. doi:10.1177/0741088301018003002.

Bazerman, C. (2009). How does science come to speak in the courts? Citations, intertexts, expert witnesses, consequential facts and reasoning. Law and Contemporary Problems, 72(1), 91-120. 
Bazerman, C. (2010). Scientific knowledge, public knowledge, and public policy: genred formation and disruption of knowledge for acting about global warming. Linguagem em (Dis)curso, 10(3), 445-463.

Bazerman, C. (2013). A theory of literate action. Fort Collins CO: WAC Clearinghouse.

Bazerman, C., \& de los Santos, R. (2005). Measuring incommensurability: Are toxicology and ecotoxicology blind to what the other sees? In R. Harris (Ed.), Rhetoric and incommensurability (424-463). West Lafayette IN: Parlor Press.

Bazerman, C., Little, J., \& Chavkin, T. (2003). The production of information for genred activity spaces. Written Communication, 20(4), 455-477. doi:10.1177/0741088303260375.

Bazerman, C., \& Rogers, P. (2008). Writing and secular knowledge apart from modern European institutions \& Writing and secular knowledge within modern European institutions. In C. Bazerman (Ed.), Handbook of research on writing (143-176). New York, NY: Routledge.

Bromwich, J.E. (2017, June 7). Defying Trump, Hawaii becomes first state to pass law committing to Paris Climate Accord. The New York Times, A1. Retrieved from https://www.nytimes. com/2017/06/07/climate/hawaii-climate-paris-trump.html.

Burkeman, A. (2003, March 4). Memo exposes Bush's new green strategy. The Guardian. Retrieved from https://www.theguardian.com/environment/2003/mar/04/usnews.climatechange

Carson, R. (1962, 1995). Silent spring. Boston: Houghton Mifflin.

Cook, J., Oreskes, N., Doran, P.T., Anderegg, W.R.L., Verheggen, B., Maibach, E.W., . . Rice, K. (2016). Consensus on consensus: a synthesis of consensus estimates on human-caused global warming. Environmental Research Letters, 11, 1-7. doi:10.1088/1748-9326/11/4/048002.

Cook, J., Lewandowsky, S., Ecker U.K.H. (2017). Neutralizing misinformation through inoculation: Exposing misleading argumentation techniques reduces their influence. PLOS ONE, 12(5). doi:10.1371/journal.pone.0175799.

Das, T.K. (1987). Strategic planning and individual temporal orientation. Strategic Management Journal, 8, 203-209. doi:10.1002/smj.4250080211.

Davenport, C. (2017). With Trump in charge, climate change references purged from website. The New York Times, Jan. 20, 2017, A20. Retrieved from https://www.nytimes.com/2017/01/20/us/ politics/trump-white-house-website.html.

Davenport, C., \& Lipton, E. (2017, June 4). How G.O.P. leaders came to view climate change as fake science. The New York Times, A1. Retrieved from https://www.nytimes.com/2017/06/03/us/ politics/republican-leaders-climate-change.html.

Davenport, C., \& Rubin, A.J. (2017). Trump signs executive order unwinding Obama climate policies. The New York Times, March 28, 2017, A1. Retrieved from https://www.nytimes. com/2017/03/28/climate/trump-executive-order-climate-change.html.

Dennis, B. (2016, December 13). Scientists are frantically copying U.S. climate data, fearing it might vanish under Trump. Washington Post, 1. Retrieved from https://www.washingtonpost.com/ news/energy-environment/wp/2016/12/13/scientists-are-frantically-copying-u-s-climate-datafearing-it-might-vanish-under-trump/?utm_term=.a0125bc5a6fd.

Freadman, A.S. (1994). Anyone for tennis? In A. Freedman \& P. Medway (Eds.), Genre and the new rhetoric (43-66). London: Taylor \& Francis.

Freadman, A.S. (2002). Uptake. In R. Coe, L. Lingard \& T. Teslenko (Eds.), The rhetoric and ideology of genre (39-53). Cresskill: Hampton Press.

Goodwin, C. (1994). Professional vision. American Anthropologist, 96(3), 606-633.

Gore, A. (1992). Earth in the balance: Ecology and the human spirit. Boston: Houghton Mifflin.

Hernández, J.C., \& Nagourney, A. (2017, June 6). As Trump steps back, Jerry Brown talks climate change in China. The New York Times, A1. Retrieved from https://www.nytimes. com/2017/06/06/world/asia/xi-jinping-china-jerry-brown-california-climate.html

Hoeppe, P., \& Berz, G. (2005). Risks of climate change--the perspective of the (re-insurance) industry. Power Engineering Society General meeting. IEEE, 1367-1370. 
Holthaus, E. (2016, December 13). Why l'm trying to preserve federal climate data before Trump takes office: The Trump administration is likely to be hostile to science. Washington Post, 1. Retrieved from https://www.washingtonpost.com/posteverything/wp/2016/12/13/why-im-trying-topreserve-federal-climate-data-before-trump-takes-office/?utm_term=.b79bbb785a4c.

Jessop, R. (2012). Coinage of the term environment: a word without authority and Carlyle's displacement of the mechanical metaphor. Literature Compass, 9(11), 708-720. doi:10.1111/ j.1741-4113.2012.00922.x.

Lorenzoni, I., Nicholson-Cole, S., \& Whitmarsh, L. (2007). Barriers perceived to engaging with climate change among the UK public and their policy implications. Global Environmental Change, 17, 445-459.

Michaels, D. (2008). Doubt is their product. Oxford: Oxford University Press.

Mills, E. (1998). The coming storm: global warming and risk management. Risk Management, 45(5), 20-25.

Mollin, H. (1993). Will global warming cool off weather underwriting? Risk Management, 40(3), 28-35.

Mooney, C., \& Eilperin, J. (2017, April 29). EPA website removes climate science site from public view after two decades. Washington Post, 1. Retrieved from https://www.washingtonpost.com/ news/energy-environment/wp/2017/04/28/epa-website-removes-climate-science-site-frompublic-view-after-two-decades/?utm_term=.c150863b34e8.

Moser, S.C. (2010). Communicating climate change: history, challenges, process and future directions. WIREs Climate Change, 1(1), 31-53. doi:10.1002/wcc.11.

Moser, S.C. (2016). Reflections on climate change communication research and practice in the second decade of the 21st century: what more is there to say? WIREs Climate Change, 7(3), 345-369. doi:10.1002/wcc.403.

Naylor, T.H., \& Schauland, H. (1976). A survey of users of corporate planning models. Management Science, 22(9), 927-937. doi:10.1287/mnsc.22.9.927.

Nisbet, M.C., \& Myers, T. (2007). Twenty years of public opinion about global warming. Public Opinion Quarterly, 71(3), 444-470. doi:10.1093/poq/nfm031.

Oreskes, N., \& Conway, E. (2010). Merchants of doubt: How a handful of scientists obscured the truth on issues from tobacco smoke to global warming. New York: Bloomsbury Press.

Proctor, R.N., \& Schiebinger, L. (Eds.) (2008). Agnotology: The making \& unmaking of ignorance. Palo Alto CA: Stanford University Press.

Revkin, A.C. (2003, June 19). Report by E.P.A. leaves out data on climate change. The New York Times, A1. Retrieved from http://www.nytimes.com/2003/06/19/us/report-by-epa-leaves-out-dataon-climate-change.html.

Revkin, A.C. (2005, June 8). Bush aide softened greenhouse gas links to global warming. The New York Times. Retrieved from http://www.nytimes.com/2005/06/08/politics/bush-aidesoftened-greenhouse-gas-links-to-global-warming.html.

Revkin, A.C. (2008). Under pressure, White House issues climate change report. The New York Times, May 30, 2008, A14. Retrieved from http://www.nytimes.com/2008/05/30/ washington/30climate.html.

Saad, L. (2017). Global warming concern at three-decade high in US. Gallup, March 12, 2017. Retrieved from http://www.gallup.com/poll/206030/global-warming-concern-three-decadehigh.aspx?g_source=CATEGORY_CLIMATE_CHANGE\&g_medium=topic\&g_campaign=tiles

Shabecoff, P. (1983, October 18). E.P.A. report says Earth will heat up beginning in 1990's. The New York Times, A1.

Smith, A.K. (1965). A peril and a hope: The scientists' movement in America, 1945-47. Chicago: University of Chicago Press. 
Sullivan, W.C., Jr. (1982) Nuclear democracy: A history of the Greater St. Louis Citizens' Committee for Nuclear Information, 1957-1967. University College Occasional Papers, 1. St. Louis, MO: Washington University.

Supran, G., \& Oreskes, N. (2017). Assessing ExxonMobil's climate change communications (1977-2014). Environmental Research Letters, 12(8). doi:10.1088/1748-9326/aa815f.

Tabuchi, H., \& Fountain, H. (2017, June 1). Bucking Trump, these cities, states and companies commit to Paris Accord. The New York Times, A12. Retrieved from https://www.nytimes. com/2017/06/01/climate/american-cities-climate-standards.html.

Tachino, T. (2012). Theorizing uptake and knowledge mobilization: A case for intermediary genre. Written Communication, 29(4), 455- 476. doi:10.1177/0741088312457908.

Waddell, C. (Ed.) (2000). And no birds sing: Rhetorical analyses of Silent Spring. Carbondale: Southern Illinois University Press.

Weart, S. $(2003,2008)$. The discovery of global warming. Cambridge MA: Harvard University Press. Retrieved from http://www.aip.org/history/climate/.

Willis, A.J. (1997). The ecosystem: An evolving concept viewed historically. Functional Ecology, 11(2), 268-271. doi:10.1111/j.1365-2435.1997.00081.x.

Wittner, L.S. (1997). Resisting the bomb: History of the world nuclear disarmament movement, 1954-1970. Palo Alto CA: Stanford University Press. 